University of Wollongong

Research Online

Faculty of Business - Papers (Archive)

Faculty of Business and Law

2014

A psychological profile of potential youth mentor volunteers

Melanie Randle

University of Wollongong, mrandle@uow.edu.au

Leonie Miller

University of Wollongong, leoniem@uow.edu.au

Joseph Ciarrochi

University of Wollongong, joec@uow.edu.au

Sara Dolnicar

University of Queensland, s.dolnicar@uq.edu.au

Follow this and additional works at: https://ro.uow.edu.au/buspapers

Part of the Business Commons

Research Online is the open access institutional repository for the University of Wollongong. For further information contact the UOW Library: research-pubs@uow.edu.au 


\title{
A psychological profile of potential youth mentor volunteers
}

\begin{abstract}
Mentoring programs rely on adult volunteers to offer disadvantaged children friendship, role modeling, and insight into the way others relate. However, with the increasing numbers of children requiring mentors, programs are finding it difficult to attract enough volunteers. This study investigates (a) community awareness of an Australian youth mentoring program, (b) the proportion of the population who would consider becoming a mentor in future, and (c) whether those who would consider it differ significantly in their psychological characteristics. While awareness of the program is low, consideration of mentoring is relatively high. Those who would consider volunteering for the program have distinct psychological characteristics, indicating that customized marketing strategies are likely to be effective in attracting them. Findings demonstrate the potential for marketing techniques to be used effectively in the youth mentoring arena and give practical guidance as to how effective campaigns could boost numbers of mentors.
\end{abstract}

Keywords

psychological, profile, potential, youth, mentor, volunteers

Disciplines

Business

Publication Details

Randle, M., Miller, L., Ciarrochi, J. \& Dolnicar, S. (2014). A psychological profile of potential youth mentor volunteers. Journal of Community Psychology, 42 (3), 338-351. 


\section{A psychological profile of potential youth mentor volunteers}

\section{Melanie Randle}

(Institute for Innovation in Business and Social Research) University of Wollongong, Australia

\section{Leonie Miller}

(School of Psychology) University of Wollongong, Australia

\section{Joseph Ciarrochi}

(School of Social Sciences and Psychology) University of Western Sydney, Australia

\section{Sara Dolnicar}

(School of Tourism) University of Queensland, Australia

\section{Corresponding author:}

Melanie Randle, Institute for Innovation in Business and Social Research, University of Wollongong, Northfields Avenue, Wollongong NSW 2522 Australia

Email:mrandle@uow.edu.au

\section{Acknowledgements}

This project was funded by the Australian Research Council Linkage Project Grant Scheme (LP0776569) and the University of Wollongong University Research Committee Small Grants Scheme. This research was conducted in partnership with CareSouth, a provider of the Aunties \& Uncles program in regional NSW. 


\title{
A psychological profile of potential youth mentor volunteers
}

\begin{abstract}
Mentoring programs rely on adult volunteers to offer disadvantaged children friendship, role modelling and insight into the way others relate. However, with the increasing numbers of children requiring mentors, programs are finding it difficult to attract enough volunteers. This study investigates (1) community awareness of an Australian youth mentoring program, (2) the proportion of the population who would consider becoming a mentor in future, and (3) whether those who would consider it differ significantly in their psychological characteristics. While awareness of the program is low, consideration of mentoring is relatively high. Those who would consider volunteering for the program have distinct psychological characteristics, indicating that customised marketing strategies are likely to be effective in attracting them. Findings demonstrate the potential for marketing techniques to be used effectively in the youth mentoring arena and give practical guidance as to how effective campaigns could boost numbers of mentors.
\end{abstract}

Keywords: youth mentors, psychological characteristics, volunteers, marketing 


\section{Introduction}

The Aunties \& Uncles program is a youth mentoring program that was established in Australia in 1974 with a mission to build a better life for disadvantaged children by giving them the chance to experience life with another family. The Aunties and Uncles - who are adult volunteers - offer the children friendship, role modelling and insight into the way other families within society live and relate to each other. Typically, children in the program spend one whole weekend per month with their Aunty or Uncle and participate in all of their usual family weekend activities. For the children, this can offer a refreshing change of scenery and new experiences, and for their birth parents it offers respite. Usually the relationship between the child and their Aunty or Uncle begins when they are aged between 0-12 years old and it is encouraged to extend for many years, often until the child reaches adulthood.

In the case of some children, the mentoring program acts as a type of early intervention designed to prevent troubled youth from progressing down a path of anti-social behaviour. Whilst the outcomes of the program are yet to be formally evaluated, anecdotally (from professionals delivering the program over many years) and from positive media stories, we know that there are many cases where the program has been successful in achieving this objective (for example Karlovsky, 2009). Since its inception, there has been an increase in the number of children identified as suitable candidates for a mentoring relationship and so waiting lists have been growing.

With the number of non-profit organisations in Australia growing to almost 60,000 (Australian Bureau of Statistics, 2009) the competition for volunteers - in this case people willing to give their time to become mentors - is also increasing. Many volunteer organisations report finding it harder and harder to attract sufficient numbers of volunteers to meet the demands for the social service they are providing, and the Aunties \& Uncles program is no different. 
In the commercial arena, the concept of market-orientation has been widely used in recent decades to inform strategic marketing planning and decision making. Market-orientation has been defined as "the organisationwide generation of market intelligence pertaining to current and future customer needs, dissemination of the intelligence across departments, and organisationwide responsiveness to it” (Kohli \& Jaworski, 1990, p. 6). Broadly speaking, the theory of market orientation stipulates that the more an organisation acquires market intelligence in order to understand the needs of their customers, and the more they use this market intelligence to drive strategic decision making, the more successful they will be in achieving their goals (Narver \& Slater, 1990). While most commonly applied in the commercial arena, the concept of market-orientation holds significant potential for improving marketing and recruitment practices for non-profit organisations also.

However, the information (or market intelligence) currently available to guide marketing and recruitment strategies for programs such as Aunties \& Uncles is limited and typically relates only to those types of people who have been attracted to the program in the past - or current mentors. If the number of volunteer mentors is to increase in order to meet demand we need to broaden the pool from which volunteers are drawn to attract different types of people who might not have considered the role in the past. In other words, we need to focus on those who have not been involved before but who are willing to consider becoming involved in future.

Currently little information is available regarding the level of awareness of mentoring programs within the general community and whether certain types of people are more likely to become involved than others. This information would allow the design of customised marketing campaigns to directly target those most likely to become involved, therefore making more efficient 
spend of the limited marketing dollars non-profit organisations have available (rather than the broadbrush, community-wide approach to marketing and recruitment typically taken).

The aims of this paper are to (1) identify levels of awareness and perceived knowledge of the Aunties \& Uncles program within the community; (2) identify the appeal of the mentoring program as measured by the proportion of the population which would consider becoming a mentor in future; (3) identify whether those who would consider joining the program in future are characterised by specific socio-demographic and psychographic profiles; and (4) recommend marketing and recruitment strategies which would be effective in reaching and motivating this particular group to become involved.

\section{Literature Review}

There has been very little research conducted to provide insight into programs such as Aunties \& Uncles in Australia. The exception is a study by Beale, Wilkes, Power and Beale (2007) who investigated the benefits of involvement in the program. These were broadly grouped into three categories: (1) enjoyment or satisfaction of the experience, (2) family relationships and (3) the difference the program is making. Similar to other forms of volunteering, the motivations for involvement in mentoring programs appear to be multifaceted, with most volunteers nominating multiple benefits from being involved. As acknowledged by the authors, however, a limitation of this study was the small geographical area in which the survey was conducted so the generalizability of results to other areas and countries is unknown.

However, virtually non-existent is information relating to the types of people likely to be involved with volunteer mentoring roles like Aunties and Uncles and the best way of attracting them. The exception was another related study by Wilkes, Beale and Cole (2007) who provided a brief description the mentors who participated in their survey. They were most likely to be female (89\%), 
aged between 30-49 years (56\%), have been involved in the program for an average of 5.8 years and heard about the program through the newspaper (39\%). However, there is no indication given of the representativity of the sample and appears to be very heavily skewed towards female mentors.

Of course, there is much literature on recruiting volunteers generally, however its applicability to mentoring programs is questionable because of the relatively involved nature of the volunteering effort (in the case of Aunties \& Uncles the child usually comes to the mentor's home to stay for the entire weekend) and the length of the commitment (which at a minimum is for a period of one year but in reality often extends for many years). In addition, the requirements that prospective Aunties and Uncles must meet - in the form of background checks, character assessments etc. - before being matched with a child go quite beyond what is usually required for volunteers for other causes. This is compounded by evidence that volunteering in general cannot be used as a proxy for volunteering for specific causes, because the types of people likely to be interested and involved in the different programs can vary significantly (see for example, Dolnicar \& Randle, 2006; Wymer, 1998, 2003).

It could be argued, therefore, that Aunties and Uncles are more similar to foster carers who undergo similar screening procedures before having a foster child placed with them. However, this is also a difficult comparison to make because having a child placed in the home full-time is quite a different proposition to committing one weekend a month, so again, it the applicability of research in this field is questionable.

There has been some research done on the similarly mentor-focussed Big Brothers Big Sisters program in the United States (De Wit et al., 2007; Roaf, Tierney, \& Hunte, 1994; Shields, 2009). Typically this research is conducted from a child welfare or sociology perspective, rather than from a marketing perspective. There is very little research appearing in Marketing-related publications on the issue of recruiting volunteers for this purpose, despite the similarities in the challenges faced here 
and in the commercial arena: how to identify those individuals most suited to your offering and then design communications strategies most likely to grab their attention.

In sum, managers of mentoring programs find themselves with very limited market-related information that is directly relevant to the particular volunteers they are trying to attract. This is despite the fact that feedback from participants in the program repeatedly reinforces the need for more marketing activity to raise the profile of these programs and "attract more and the right volunteers” (Wilkes et al., 2007, p.296). Furthermore, as birth parents have expressed, “this program is [highly] valuable in the emotional and physical development of our children”, but researchers acknowledge that "the process is constrained by number of volunteers" (Beale et al., 2007, p.175).

\section{Methodology}

\section{Fieldwork Administration}

Data was collected in November - December 2009 using an online panel which is maintained to ensure it is representative of the Australian population. This method of data collection was appropriate because it enabled a large nationally representative sample of 1,098 participants to be collected within the budget and time constraints of the project. Invitations to participate were emailed to a nationally representative sample. Participants who accepted were then screened to ensure the resultant sample was representative for State of residence, age (18-65) and sex. In addition, soft quotas were implemented for other demographic variables including household income, education, employment status and marital status. Quotas were determined using Australian Bureau of Statistics census data. 


\section{Measures}

Measures were grouped into two categories. Firstly, respondents answered questions relating specifically to Aunties \& Uncles to assess levels of awareness, knowledge and appeal of the program. Secondly, and for the purposes of segment profiling, participants answered questions relating to their socio-demographic and psychometric characteristics and media usage.

Awareness, knowledge and consideration of Aunties \& Uncles. To measure program awareness participants were asked “Have you heard of the Aunties \& Uncles program?” and could answer yes or no. Perceived knowledge of the program was measured by asking "Do you know what the Aunties \& Uncles program is?” and again could answer yes or no. All participants were then given the following explanation of the Aunties \& Uncles program:

“The Aunties \& Uncles program involves adult volunteers having a child from a disadvantaged background come to stay with them for one weekend a month to experience life with another family. Aunties and Uncles provide children with friendship, role modelling, and time out from stressful situations. The relationship starts when the child is aged between 0-12, however it can often extend for many years until the child is an adult”.

Participants were then asked "Would you consider becoming an Aunty or Uncle in future?” and could answer yes or no. These measures were developed through consultation with Aunties \& Uncles professionals and pre-testing of question wording to ensure that participants understood the construct meaning as intended.

Socio-demographic measures. Participants provided socio-demographic information including sex, age, education, state and area of residence, whether they rent or own their home and their political preference. They also answered questions relating to their household situation including their marital and relationship status, whether they have children and if they live at home, 
whether there were other people living in the household and whether any other languages are spoken at home. Participants gave information relating to their employment and wealth, including employment status, individual and household income and anticipated retirement age.

In addition, a number of questions investigated participants’ knowledge and involvement with altruistic behaviours and experience with disadvantaged or disabled people. These were included because they relate to the similarly altruistic behaviours of volunteering and foster care, and were hypothesised to be related to an individual's likelihood of mentoring in future. These included whether they had volunteered in the past 12 months, had experience with disabled people at work or home, had knowledge of what foster care is, would consider being a foster carer in future and if they would like to receive information about becoming a foster carer.

Psychometric measures. Established and validated psychometric scales were used to measure environmental/personal resources and personal characteristics. Individuals with "high environmental/personal resources” included those who had high quality social support, high quality relationship with a significant other, high perceived wealth, and a highly satisfying life. Personal characteristics focused on stable individual difference characteristics including the extent to which people were self-directed and effective (hope, effective problem solving orientation), socially cooperative (affective and cognitive empathy), and expressed religious faith.

Social support. We utilized the multidimensional scale of perceived social support (Zimet, Dahlem, Zimet, \& Farley, 1988). Participants rate 12 statements on a seven-point scale ranging from strongly disagree (1) to strongly agree (7). The scale has three subscales, social support from family (e.g. "My family really tries to help me”, alpha =.93), friends (e.g. "I have friends with whom I can share my joys and sorrows", alpha=.94), and significant others (e.g. "There is a special person who is around when I am in need”, alpha $=.96)$. 
Perceived relationship quality. The Perceived Relationship Quality Components (PRQC) inventory measures individuals' evaluations of their relationship satisfaction, commitment, intimacy, trust, passion, and love (Fletcher, Simpson, \& Thomas, 2000; Grigg, Fletcher, \& Fitness, 1989). The scale consists of six items (e.g. “How satisfied are you with your relationship?”) and is rated from not at all (1) to extremely (7). Cronbach’s alpha was .90. The scale has been related to the extent that couples spontaneously produce explanations for both self and partner behaviours that appear designed to enhance the existing levels of happiness and love (Grigg et al., 1989).

Perceived wealth. Participants indicated the extent to which they thought their family was very poor (1), quite poor (2), neither rich nor poor (3), well off (4), and rich (5). They were also asked how happy they were with their family’s financial position, ranging from very unhappy (1) to very happy (5). The two measures were moderately correlated $(r=.54)$ and were combined to form a moderately reliable scale (alpha $=.66)$.

Life satisfaction. The Life Satisfaction Scale (Diener, Emmons, Larsen, \& Griffin, 1985) asks participants the extent to which they agree (1) or disagree (7) with each of five statements related to life satisfaction (e.g. "In most ways my life is close to my ideal”, alpha $=.90$ ). The scale is wellvalidated (for a review see Diener, Suh, Lucas, \& Smith, 1999).

Hope. Trait hope involves the belief that one can produce "routes to desired goals" (Snyder, 2000, p.8). High hope individuals believe they can begin and maintain movement towards their goals (agency thinking) and produce plausible routes to the goals (pathways thinking). Four items measured pathways thinking (e.g. "I can think of many ways to get out of a jam”, alpha = .76) and agency thinking (e.g. "I energetically pursue my goals”, alpha = .76). The total scale had an alpha of .85. Items are rated on a four point scale ranging from definitely false (1) to definitely true (4). 
Problem solving orientation. Negative problem orientation (NPO) is the extent to which people do not believe they can effectively cope with problems and try to avoid rather than solve them (Frauenknecht \& Black, 2004). Effective problem orientation involves firstly being sensitive to detecting problems and prepared to engage in problem-solving activity, secondly being able to focus on adaptive problem-solving thoughts instead of unproductive thoughts, and thirdly persisting when obstacles are encountered (D'Zurilla \& Nezu, 1999). The nine-item Problem Orientation Scale includes three subscales: cognitive, emotional and behavioural (Frauenknecht \& Black, 1995). Participants responded using a 5-point rating scale with high scores indicating an avoidance of problems. The instrument has good discriminant, convergent, and predictive validity (Ciarrochi, Leeson, \& Heaven, 2009; Ciarrochi \& Scott, 2006; Ciarrochi, Scott, Deane, \& Heaven, 2003).

Religious faith. Participants were asked whether they agreed that "Religion plays an important role in my life”, and answered from 1 (strongly disagree) to 5 (strongly agree).

Empathy. Empathy is important in the development of relationships and relates to helping behaviour, lower levels of antisocial behaviour, and lower prejudice (Albiero, Matricardi, Speltri, \& Toso, 2009; Davis, 1983). We utilized the Basic Empathy Scale (Jolliffe \& Farrington, 2006) which consists of two subscales: affective empathy (e.g. "After being with a friend who feels sad about something, I usually feel sad", alpha=.76) and cognitive empathy (e.g. "When someone is feeling ‘down', I can usually understand how they feel”, alpha = .83). Past research has established the factorial validity of the scale, and demonstrated that it relates in expected ways to other measures of empathy and personality (Jolliffe \& Farrington, 2006).

Media usage. Participants indicated which newspapers they read most often, which television stations they watch most often and which types of radio stations they listen to most often. Participants also indicated which magazines they read and how often they use the internet. 


\section{Analysis and Results}

\section{Sample Description}

The sample was structured to ensure it was nationally representative for sex, age, and State of residence. This resulted in the sample being $50 \%$ male and 50\% female. Thirty-three per cent were from New South Wales, 25\% from Victoria and 20\% from Queensland. Regarding age, the middle age groups (25-34, 35-44 and 45-54 years) were most highly represented and summed to $66 \%$ of the total sample. Forty-nine per cent of the sample was married, $23 \%$ had a trade certificate and 22\% was university qualified, 43\% worked full-time and 40\% came from households earning between \$800-\$1700 per week.

\section{Program Awareness and Knowledge.}

The majority of the sample (86\%) had not heard of the Aunties \& Uncles program. The $14 \%$ that was aware of the program were then asked if they knew what the program was. Half of these (7\%) did know what it was; the other 7\% indicated that although they had heard of it they did not know what it was.

\section{Future Consideration of Mentoring}

Despite low levels of unprompted awareness of the program, almost half of the sample (47\%) indicated they would consider becoming mentors in future.

\section{Profile of Potential Mentors}

Of the initial sample of 1,098 four cases were discounted in the present analyses because they were, or had been, involved in the Aunties \& Uncles program previously. Table 1 presents the mean 
values for a number of demographic variables separately for those who would consider mentoring in future (the “yes” group) and those who would not (the “no” group).

(Insert Table 1 about here)

Socio-demographic profile. Table 2 contains a series of between-groups analyses testing for differences between groups in terms of demographic and other categorical variables. Variables are grouped according to residence, home environment, wealth, training, knowledge, and other. All tests adopted a significance criterion of $\alpha=.01$. Categorical variables were examined using $\chi^{2}$ tests of independence, while ordinal and continuous variables used ANOVA procedures. Table 2 also includes estimates of effect sizes for the variables analysed so that those variables likely to differentiate the “yes” from the "no" group are identified.

(Insert Table 2 about here)

Respondents who would consider mentoring in future were significantly younger and more significantly likely to be female. While the age effect was small to medium, the effect of sex was quite small. Neither state nor the area of residence impacted their interest in the role. The ratio of home owners to renting respondents was significantly smaller in the "yes” than "no" group, but the overall effect was small. Regarding home environment, the groups did not differ on marital and relationship status, numbers of people in the household, number of children in the home and whether a second language was spoken at home. A marginally greater proportion of individuals in the "no" group had children, but the difference was once again small. Furthermore, while a significantly greater number of "no" than “yes” respondents had older children who had left home, consistent with the profile of this group being older, this difference was not great.

Regarding employment status, the "no” group had a significantly greater proportion of retirees. This is consistent with both the greater mean age of these respondents and the greater proportion of 
respondents with older children. However, the “yes” group reported small but significantly greater household income, and this was also reflected by fewer low income individuals in this group.

Respondents in paid employment but not retired were asked at what age when they anticipated retiring. These data for the most part formed a normal distribution except for a number of extreme responses - for example 24 or 99 years old. These extreme estimates were considered likely to be expressions of either desire to leave work or resignation to work rather than a realistic account of an anticipated retirement point. Therefore, the data was trimmed before further analysis was conducted, including responses between 48 and 77 years only. An ANOVA revealed that there was no significant difference in the mean anticipated retirement ages between the groups, $F(1,819)=3.75, p$ $=.053\left(\mathrm{~N}_{\text {yes }}=414, \mathrm{~N}_{\mathrm{no}}=407\right)$. There was also no difference between the groups with respect to education.

A difference in the relative proportion of individuals within the groups who had experience with disabled people was compared using a $\chi^{2}$ test of independence, highlighting a significantly greater number in the “yes” than "no” group. A significantly greater proportion of "yes” respondents were also found to know past or present foster carers, suggesting that knowledge of the foster caring situation does not detract from the consideration to become a mentor. While the effects of these variables were small, it is possible that more concrete expectations from knowledge of the fostering context might encourage individuals to participate in it.

There was no significant difference in the political preferences expressed by each group. A small effect of volunteering was found with a significantly greater number of volunteers present in the "yes” group. Indicators that identified whether respondents would consider more extended forms of fostering in the future and whether they would like information on fostering both found 
significantly greater representation in the “yes” group. These effects were medium to large suggesting that mentoring programs might present an entry point for foster caring in the future.

Psychometric profile. Psychometric variables were examined by a series of ANOVAs that applied a significance criterion of $\alpha=.01$. Results and effect sizes are presented in Table 3.

(Insert Table 3 about here)

With the exception of relationship quality where no difference was identified, the measures of environmental and personal resources were significantly higher for the “yes” group. Individuals who would consider youth mentoring reported greater incremental social support from family and friends, social support in total, life satisfaction and perceived wealth. The "yes" individuals tend to be better resourced/supported in their relationships with others and more secure in their current life positions.

Personal characteristics variables were subdivided into two sets: self-directedness (hope and problem-solving orientation) and social cooperativeness (empathy and religious faith). The selfdirectedness variables identified that the “yes” group had significantly greater Hope-Pathways, Hope-Agency and Hope-Total measures, and significantly smaller problem solving scores. Furthermore, these variables produced moderate effect sizes. Consequently, individuals considering youth mentoring felt more able to determine ways to achieve their goals and capable of carrying out their plans towards goal completion, and were more positive about their problem-solving capacities.

The “yes” group had significantly higher levels of cognitive empathy and total empathy, while the result for affective empathy was marginally significant. Specifically, cognitive empathy produced a medium effect between the groups. Therefore these respondents rated themselves as better at understanding the emotions of others and more able to use this insight to find ways to resolve emotional issues. The importance of religion also did not vary between groups. Furthermore, the 
proportion of individuals who had a religious faith also did not vary between groups, $\chi^{2}(1)=2.29, p$ $=.131$.

Media usage profile. Differences in media usage were examined by performing $\chi^{2}$ tests of independence and the same significance criterion as adopted above. Results are provided in Table 4. The “yes” group had a significantly greater proportion of viewers who favoured Prime/Ten television networks, while a greater relative proportion of “no” respondents preferred WIN (these stations represent the three major free-to-air commercial television networks in Australia). However this effect was small. There were no significant differences in radio format preference or internet usage. The difference in preference for newspapers was marginally significant, with a tendency for 'yes' respondents to prefer local or regional papers and “no” respondents to not read newspapers.

\section{(Insert Table 4 about here)}

Magazine usage by group was not statistically analyzsed as the respondents could nominate multiple publications, and therefore this data violated the assumption of independence. However, the resulting distributions of magazine use did not appear to be different between “yes’ and “no” groups.

Finally multivariate analysis was performed to examine the distinctive factors that increase the chance of an individual considering mentoring in future. Logistic regression was chosen because of the dichotomous nature of the dependent variable. The predictor variables in the model were those that showed at least a small to medium relationship with the dependent variable in previous analyses, and included age, the extent people would consider foster caring in the future (interest), the requesting of more information on foster care, cognitive empathy, and hope.

All independent variables were forced simultaneously into the equation and therefore acted as covariates for each other. The resulting model explained substantial variance (Cox \& Snell $\left.\mathrm{R}^{2}=.36\right)$ 
and resulted in 83\% successful "no" classifications and 78\% correct “yes” classifications, with an overall accuracy rate of $80.8 \%$.

Age $(B=-.018, S E=.006, \operatorname{Exp}(B)=.98)$, foster caring interest $(B=2.34, S E=.17, \operatorname{Exp}(B)=$ 10.41), information requested $(\mathrm{B}=-1.02, \mathrm{SE}=.23, \operatorname{Exp}(\mathrm{B})=.36)$, and cognitive empathy $(\mathrm{B}=.065$, $\mathrm{SE}=.017, \operatorname{Exp}(\mathrm{B})=1.07)$ all significantly predicted consideration of becoming a mentor in future $(\mathrm{p}$ $<.05$ ), whereas hope was non-significant, $p>.10$. Thus, the odds of considering becoming a mentor in future in this sample increased with younger age, greater foster caring interest, greater requesting of foster care information, and higher cognitive empathy.

\section{Conclusions}

This study produced the following key findings:

(1) Eighty-six per cent of respondents have never heard of the Aunties \& Uncles mentoring program, indicating the base awareness level is low. It also highlights the potential for targeted communication messages to increase the awareness and recruit more mentors.

(2) Forty-seven per cent of respondents would consider mentoring in future, indicating substantial potential for future recruitment of new mentors. This figure (almost half of the sample) suggests that this type of volunteering is something that many individuals see as positive and a role they would be capable of performing.

(3) Individuals who would consider youth mentoring have distinct characteristics when compared with those who would not. These differences are present in terms of sociodemographics, psychometric characteristics, and altruistic experience and behaviour. 
These findings are useful for managers of youth mentoring programs because they provide insight regarding (1) the personal characteristics of potential mentors; (2) where they are likely to be found and (3) the types of messages which are likely to be meaningful and motivating for them.

For example, we know that individuals who would consider becoming youth mentoring volunteers are more likely to be younger, female, are not yet retired, with a trend of having fewer children. They are also more likely to have volunteered in the past and would consider other types of altruistic roles in future, such as foster caring. This information enables communications to be directed at locations where these types of people are most likely to be found, such as women's sporting competitions to reach younger females or professional associations or workplaces to reach individuals not yet at retirement age. Given that this group is also likely to have experience in other altruistic roles there may be opportunities for cross-promotions with other voluntary organisations (or sharing of volunteers) where complimentary volunteering experiences are identified.

The differences identified in terms of psychological characteristics can also guide the development of messages more likely to motivate potential mentors. For example, we know that those who would consider youth mentoring have higher levels of empathy and hope and are more positive about their problem solving skills. Images and messages emphasizing the disadvantage of children in the program and the ability of mentors to positively impact them in the long-term are likely to reinforce and support these personal qualities and therefore appeal to those who see themselves as having them.

No specific media channel was identified as more effective in reaching potential mentors, which suggests that recruitment managers have flexibility to choose channels that fit within their organisation’s circumstances and budgetary constraints. 
Future research on youth mentor volunteers could include investigation of the structure of the potential market of volunteer mentors. For example, segmentation studies which compare individuals who currently do act as mentors, volunteers for other causes and individuals who currently do not volunteer at all. Understanding these differences would allow managers to design marketing and communications campaigns to target those types of individuals who are most likely to join the program. In addition, follow up studies which investigate the seriousness of people's consideration of the program (as compared to general consideration) and the conversion rate of those considering the role who actually join the program would provide useful insight into this specific form of volunteering behaviour. 


\section{References}

Albiero, P, Matricardi, G, Speltri, D, \& Toso, D. (2009). The assessment of empathy in adolescence: A contribution to the italian validation of the "basic empathy scale". Journal of Adolescence, 32, 393-408.

Australian Bureau of Statistics. (2009). Australian national accounts: Non-profit institutions satelite account Retrieved 13 March, 2010, from http://www.ausstats.abs.gov.au/Ausstats/subscriber.nsf/0/661F486077ACD72BCA25763 40019C6C8/\$File/52560_2006-07.pdf

Beale, B, Wilkes, L, Power, B, \& Beale, R. (2007). Aunties and uncles co-operative family project: The experiences of children, volunteers and parents. Child: Care, Health and Development, 34(2), 173-179.

Ciarrochi, J, Leeson, P, \& Heaven, PCL. (2009). A longitudinal study into the interplay between problem orientation and adolescent well-being. Journal of Counseling Psychology, 56, 441-449.

Ciarrochi, J, \& Scott, G. (2006). The link between emotional competence and well-being: A longitudinal study. British Journal of Guidance \& Counselling, 34(2), 231-243.

Ciarrochi, J, Scott, G, Deane, FP, \& Heaven, PC. (2003). Relations between social and emotional competence and mental health: A construct validation study. Personality and Individual Differences, 35(8), 1947-1963.

D'Zurilla, TJ, \& Nezu, AM. (1999). Problem-solving therapy : A social competence approach to clinical intervention (2nd ed.). New York, NY: Springer Pub.

Davis, M. (1983). Measuring individual differences in empathy: Evidence for a multidimensional approach. Journal of Personality and Social Psychology, 44, 113-126.

De Wit, DJ, Lipman, E, Manzano-Munguia, M, Bisanz, J, Graham, K, Offord, DR, O'Neill, E, Pepler, D, \& Shaver, K. (2007). Feasibility of a randomized controlled trial for evaluating 
the effectiveness of the big brothers big sisters community match program at the national level. Children and Youth Services Review, 29(2), 383-404.

Diener, E, Emmons, RA, Larsen, RJ, \& Griffin, S. (1985). The satisfaction with life scale. Journal of Personality Assessment, 49(1), 71-75.

Diener, E, Suh, EM, Lucas, RE, \& Smith, HL. (1999). Subjective well-being: Three decades of progress. Psychological Bulletin, 125(2), 276-302.

Dolnicar, S, \& Randle, M. (2006). Who donates time to the benefit of environmental and animal rights? Profiling volunteers from an international perspective. Paper presented the Australasian Nonprofit and Social Marketing Conference CD Proceedings, Newcastle, New South Wales.

Fletcher, GJ, Simpson, JA, \& Thomas, G. (2000). The measurement of perceived relationship quality components: A confirmatory factor analytic approach. Personality and Social Psychology Bulletin,, 26, 340-354.

Frauenknecht, M, \& Black, DR. (1995). Social problem-solving inventory for adolescents (spsi-a): Development and preliminary psychometric evaluation. Journal of Personality Assessment, 64(3), 522-539.

Frauenknecht, M, \& Black, DR. (2004). Problem-solving training for children and adolescents. In EC Chang, TJ D'Zurilla \& LJ Sanna (Eds.), Social problem solving: Theory, research, and training (pp. 153-179). Washington, DC: American Psychological Association.

Grigg, F, Fletcher, GJO, \& Fitness, J. (1989). Spontaneous attributions in happy and unhappy dating relationships. Journal of Social and Personal Relationships, 6(1), 61-68.

Jolliffe, D, \& Farrington, D. (2006). Development and validation of the basic empathy scale. Journal of Adolescence, 29, 589-611.

Karlovsky, B. (2009, 16 December). Mentors' money crisis: Aunties and uncles tinkering on the brink of collapse, Paramatta Advertiser, p. 67. 
Kohli, AK, \& Jaworski, BJ. (1990). Market orientation: The construct, research propositions, and managerial implications. Journal of Marketing, 54(2), 1-18.

Narver, JC, \& Slater, SF. (1990). The effect of a market orientation on business profitability. Journal of Marketing, 54(4), 20-35.

Roaf, PA, Tierney, JP, \& Hunte, DEI. (1994). Big brothers / big sisters: A study of volunteer recruitment and screening. Philadelphia: Public/Private Ventures.

Shields, PO. (2009). Young adult volunteers: Recruitment appeals and other marketing considerations. Journal of Nonprofit and Public Sector Marketing, 21(1), 139-159.

Snyder, CR. (2000). Handbook of hope : Theory, measures, \& applications. San Diego, Calif. ; London: Academic.

Wilkes, L, Beale, B, \& Cole, R. (2007). Aunties and uncles co-operative family project ltd. Contemporary Nurse, 23(2), 291-302.

Wymer, WW. (1998). Youth development volunteers: Their motives, how they differ from other volunteers and correlates of involvement intensity. Journal of Nonprofit and Voluntary Sector Marketing, 3(4), 321-336.

Wymer, WW. (2003). Differentiating literacy volunteers: A segmentation analysis for target marketing. International Journal of Nonprofit and Voluntary Sector Marketing, 8(3), 267-285.

Zimet, G, Dahlem, N, Zimet, S, \& Farley, G. (1988). The multidimensional scale of perceived social support. Journal of Personality Assessment, 52, 30-41. 


\section{TABLES}

Table 1. Mean values of age, number of people in the household, personal income, household income, educational level, and anticipated retirement age by whether or not respondents would consider Aunties \& Uncles in the future.

\begin{tabular}{lcc}
\hline \multicolumn{1}{c}{ Measure } & Yes & No \\
\hline$N$ & 518 & 576 \\
Age (years) & $38.15(12.34)$ & $43.30(13.06)$ \\
Personal income $^{\dagger a}$ & $4.77(2.31)$ & $4.62(2.27)$ \\
Household income $^{\dagger \mathrm{b}}$ & $5.27(1.73)$ & $4.97(1.85)$ \\
Number of people in the household $^{\dagger \mathrm{a}}$ & $2.89(1.51)$ & $2.74(1.30)$ \\
Level of education $^{\dagger \mathrm{c}}$ & $3.97(1.76)$ & $3.78(1.75)$ \\
${\text { Anticipated retirement age } N^{d}}^{d}$ & 430 & 425 \\
Anticipated retirement age & $63.97(7.42)$ & $62.76(7.34)$ \\
\hline
\end{tabular}

Note. Standard deviations are given in brackets.

${ }^{\dagger}$ These values refer to scales.

${ }^{a}$ Personal Income (\$/week): 1- \$0-\$149, 2 - \$150-\$249, 3 - \$250-\$399, 4 - \$400-\$599, 5 - \$600-\$799, 6 - \$800$\$ 999,7$ - \$1,000-\$1,299, 8 - \$1,300-\$1,599, 9 - \$1,600-\$1,999, 10 - \$2,000 or more.

${ }^{\mathrm{b}}$ Household income (\$/week): 1 - \$0-\$249, 2 - \$250-\$499, 3 - \$500-\$799, 4 - \$800-\$1,199, 5 - \$1,200-\$1,699, 6 $\$ 1,700-\$ 2,499,7$ - $\$ 2,500$ or more.

${ }^{\mathrm{c}}$ Level of education: 1 - Below Year 10, 2 - Year 10, 3 - Year 12, 4 - Certificate I, II, III, IV, 5 - Diploma /

Advanced Diploma, 6 - Bachelor Degree, 7 - Graduate Diploma / Graduate Certificate, 8 - Postgraduate Degree.

${ }^{\mathrm{d}}$ Some respondents were already retired. 
Table 2. The results of between-groups analysis on each of the demographic measures by whether or not respondents would consider Aunties \& Uncles in the future.

\begin{tabular}{|c|c|c|c|c|}
\hline Measure & Test & $N$ & Test statistic & Effect size \\
\hline Sex & $\chi^{2}$ & 1094 & $\chi^{2}(1)=10.04 *$ & $.10^{\mathrm{a}}$ \\
\hline Age & ANOVA & 1094 & $F(1,1092)=44.60 * *$ & $.40^{\mathrm{b}}$ \\
\hline \multicolumn{5}{|l|}{ Residence } \\
\hline State of residence & & 1094 & $\chi^{2}(7)=8.01$ & $.09^{\mathrm{a}}$ \\
\hline $\begin{array}{l}\text { Area of residence (urban, regional, } \\
\text { rural) }\end{array}$ & $\chi^{2}$ & 1094 & $\chi^{2}(2)=2.57$ & $.05^{\mathrm{a}}$ \\
\hline Accommodation is rental or owned & $\chi^{2}$ & 1094 & $\chi^{2}(1)=11.04 * *$ & $.10^{\mathrm{a}}$ \\
\hline \multicolumn{5}{|l|}{ Home environment } \\
\hline Marital status & $\chi^{2}$ & 1094 & $\chi^{2}(4)=7.04$ & $.08^{\mathrm{a}}$ \\
\hline Relationship status & $\chi^{2}$ & 563 & $\chi^{2}(4)=2.77$ & $.07^{\mathrm{a}}$ \\
\hline Number of people in the household & ANOVA & 1094 & $F(1,1092)=2.91$ & $.10^{\mathrm{a}}$ \\
\hline A second language spoken at home & $\chi^{2}$ & 1094 & $\chi^{2}(1)=0.41$ & $.02^{\mathrm{a}}$ \\
\hline Children & $\chi^{2}$ & 1094 & $\chi^{2}(1)=6.13^{\dagger}$ & $.07^{\mathrm{a}}$ \\
\hline Number of children in the home & $\begin{array}{l}\text { Wilcoxon rank } \\
\text { sum }\end{array}$ & 1094 & $z=-1.02$ & $.03^{\mathrm{c}}$ \\
\hline $\begin{array}{l}\text { Number of children }>18 \text { years no } \\
\text { longer in the home }\end{array}$ & $\begin{array}{l}\text { Wilcoxon rank } \\
\text { sum }\end{array}$ & 1094 & $z=-3.13 *$ & $.09^{\mathrm{c}}$ \\
\hline \multicolumn{5}{|l|}{ Wealth } \\
\hline Employment status & $\chi^{2}$ & 1094 & $\chi^{2}(6)=27.76 * *$ & $.16^{\mathrm{a}}$ \\
\hline Personal income & ANOVA & 1094 & $F(1,1092)=1.102$ & $.06^{\mathrm{b}}$ \\
\hline Household income & ANOVA & 1094 & $F(1,1092)=7.42 *$ & $.17^{\mathrm{b}}$ \\
\hline Anticipated retirement age & ANOVA & 1094 & $F(1,853)=5.71$ & $.16^{\mathrm{b}}$ \\
\hline \multicolumn{5}{|l|}{ Training } \\
\hline Education & ANOVA & 1094 & $F(1,1092)=2.89$ & $.10^{\mathrm{b}}$ \\
\hline \multicolumn{5}{|l|}{ Knowledge } \\
\hline $\begin{array}{l}\text { Experience with persons with } \\
\text { disability either at work or at home }\end{array}$ & $\chi^{2}$ & 1094 & $\chi^{2}(1)=7.77 *$ & $.08^{\mathrm{a}}$ \\
\hline Knowledge of foster caring situation & $\chi^{2}$ & 1094 & $\chi^{2}(1)=9.44 *$ & $.09^{\mathrm{a}}$ \\
\hline \multicolumn{5}{|l|}{ Other } \\
\hline Political preference & $\chi^{2}$ & 1094 & $\chi^{2}(6)=11.26$ & $.10^{\mathrm{a}}$ \\
\hline Volunteered in the last 12 months & $\chi^{2}$ & 1094 & $\chi^{2}(1)=29.79 *$ & $.17^{\mathrm{a}}$ \\
\hline Consider fostering in the future & $\chi^{2}$ & 1094 & $\chi^{2}(1)=403.52 *$ & $.61^{\mathrm{a}}$ \\
\hline Asked for foster caring info & $\chi^{2}$ & 1094 & $\chi^{2}(1)=153.27 *$ & $.37^{\mathrm{a}}$ \\
\hline
\end{tabular}

Note. ${ }^{\dagger}$ Marginally significant. ${ }^{*} p<.01 .{ }^{* *} p<.001$.

${ }^{\text {a }}$ Effect size as measured by $w$. According to the Cohen's conventions for this measure, $w=.10$ is considered small, $w=$ .30 is medium and $w=.50$ is large.

${ }^{\mathrm{b}}$ Effect size as measured by $d$. According to the Cohen's conventions for this measure, $d=.20$ is considered small, $d=$ .50 is medium and $d=.80$ is large.

${ }^{\mathrm{c}}$ Effect size as measured by $r$. According to the Cohen's conventions for this measure, $r=.10$ is considered small, $r=$ .30 is medium and $r=.50$ is large. 
Table 3. The reliabilities, mean values, and results of analyses of the psychometric variables by whether or not respondents would consider Aunties \& Uncles in the future.

\begin{tabular}{lccccc}
\hline Measure $^{\ddagger}$ & $\begin{array}{c}\text { Cronbach’s } \\
\alpha\end{array}$ & Yes & No & $F$ & Effect size $^{b}$ \\
\hline Environmental/personal resources & & & & & \\
Social support (MSPSS) & .94 & $68.01(12.71)$ & $64.47(13.98)$ & $9.92^{*}$ & .26 \\
$\quad$ Significant other & .96 & $23.35(5.71)$ & $22.26(5.73)$ & $6.66^{*}$ & .19 \\
$\quad$ Family & .93 & $22.20(5.20)$ & $21.37(5.40)$ & $29.24^{* *}$ & .16 \\
$\quad$ Friends & .94 & $22.46(4.46)$ & $20.84(5.36)$ & $19.09^{* *}$ & .32 \\
Relationship quality & .90 & $29.49(5.23)$ & $28.92(5.98)$ & 1.95 & .10 \\
Perceived wealth & .66 & $6.45(1.19)$ & $6.21(1.32)$ & $9.76^{*}$ & .19 \\
Life satisfaction & .90 & $23.16(6.44)$ & $21.97(6.67)$ & $9.08^{*}$ & .18 \\
Personal characteristics & & & & & \\
Hope-Total & .85 & $24.36(3.11)$ & $23.12(3.31)$ & $40.88^{* *}$ & .39 \\
Hope-Pathways & .77 & $12.44(1.66)$ & $11.83(1.74)$ & $35.63^{* *}$ & .36 \\
Hope-Agency & .76 & $11.92(1.75)$ & $11.29(1.93)$ & $31.85^{* *}$ & .34 \\
Problem-solving orientation & .86 & $18.89(6.52)$ & $20.92(6.66)$ & $25.78^{* *}$ & .31 \\
Empathy Total (BES) & .82 & $73.73(8.39)$ & $70.59(8.99)$ & $35.37^{* *}$ & .36 \\
$\quad$ Cognitive empathy & .83 & $35.77(4.72)$ & $33.54(4.97)$ & $57.52^{* *}$ & .46 \\
$\quad$ Affective empathy & .76 & $37.96(5.73)$ & $37.05(5.98)$ & $6.56^{\dagger}$ & .16 \\
Importance of religion & & $3.24(1.22)$ & $3.32(1.25)$ & 0.68 & .07 \\
$N^{a}$ & & 518 & 576 & & \\
\hline
\end{tabular}

Note. Standard deviations are given in brackets.

${ }^{\ddagger}$ These variables refer to the scales outlined in the Method section.

${ }^{\dagger}$ Marginally significant. ${ }^{*} p<.01 .{ }^{* *} p<.001$.

${ }^{a}$ These refer to the respondent numbers in each group except for relationship quality and importance of religion.

Relationship quality had 358, and 418 respondents for "Yes" and "No" groups, respectively. Importance of religion had 283, and 303 respondents for "Yes" and "No" groups, respectively.

${ }^{\mathrm{b}}$ Effect size is given by Cohen's $d$. According to the conventions for this measure, $d=.20$ is considered small, $d=.50$ is medium and $d=.80$ is large. 
Table 4. The results of between-groups analysis on media usage measures by whether or not respondents would consider Aunties \& Uncles in the future.

\begin{tabular}{lcccc}
\hline Measure & Test & $N$ & Test statistic & Effect size $^{a}$ \\
\hline TV & $\chi^{2}$ & 1094 & $\chi^{2}(7)=18.84^{*}$ & .13 \\
Radio & $\chi^{2}$ & 1094 & $\chi^{2}(10)=21.49$ & .14 \\
Newspapers & $\chi^{2}$ & 1094 & $\chi^{2}(6)=16.02^{\dagger}$ & .12 \\
$\begin{array}{l}\text { Frequency of internet } \\
\text { use }\end{array}$ & $\chi^{2}$ & 1094 & $\chi^{2}(3)=9.19$ & .09 \\
\hline
\end{tabular}

Note. ${ }^{\dagger}$ marginally significant. ${ }^{*} p<.01$.

${ }^{a}$ Effect size as measured by $w$. According to the Cohen's conventions for this measure, $w=.10$ is considered small, $w=.30$ is medium and $w=.50$ is large. 